\title{
Patterns of Soil Arthropod Community in Different Zones of Olive Cultivation in Crete, Greece
}

\author{
Vasileios D. Gkisakis ${ }^{*}$, Elisavet Georgopoulou, Emannouil Kabourakis \\ Olive and Agroecological Production Systems Laboratory, Department of Agriculture School of Agricultural Sciences, Hellenic \\ Mediterranean University, Heraklion, Crete, Greece.
}

\begin{abstract}
How to cite this paper: Vasileios D. Gkisakis, Elisavet Georgopoulou, Emannouil Kabourakis. (2021) Patterns of Soil Arthropod Community in Different Zones of Olive Cultivation in Crete, Greece. International Journal of Food Science and Agriculture, 5(2), 233-240.

DOI: 10.26855/ijfsa.2021.06.005
\end{abstract}

Received: March 12, 2021

Accepted: April 10, 2021

Published: April 23, 2021

*Corresponding author: Vasileios D. Gkisakis, Olive and Agroecological Production Systems Laboratory, Department of Agriculture School of Agricultural Sciences, Hellenic Mediterranean University, Heraklion, Crete, Greece.

Email: gkisakis@hmu.gr

\begin{abstract}
Olive production is a major agricultural activity for the Mediterranean basin. However, the knowledge on biodiversity patterns in olive agroecosystems is not sufficient known for important taxa like soil arthropods, in order to support sustainable farming approaches. In the present study, we hypothesised that different zones of olive cultivation, namely hills and plains, would be discriminated with regards to their effect on ground-dwelling arthropods, confirming previous research contacted in the same area of interest (Crete, Greece) but expanded in terms of production periods, study sites and by focusing on important taxa, like Coleoptera. The comparisons in terms of arthropod total abundance, richness and diversity, delivered statistically significant differences between orchards in hills and plains; arthropod diversity appeared to be seasonally higher in hills, although total abundance and richness were similar for both zones. Abundance of specific taxa were significantly different for three taxa in autumn, as well as for another four coleopteran families, while in spring difference appeared for six taxa, and six coleopteran families. The results were comparable with the previous study conducted in the area, indicating the discriminatory effect of the cultivation zones when arthropod biodiversity is considered. Further research would be required to confirm the interaction and the subsequent importance of agroecological attributes, like landscape, expecting to provide a biodiversity-based framework for olive farming.
\end{abstract}

\section{Keywords}

Olive Orchards, Farming, Agrobiodiversity, Agroecology

\section{Introduction}

Agricultural land already covers approximately $40 \%$ at global scale, while it hosts a plethora of species and habitats [1]. Consequently, agroecosystems and their biodiversity are regarded as facing serious threats, not only because of the implementation of intensive farming approaches [2], but also due to habitat fragmentation and homogenization of the agricultural landscape [3, 4]. Such negative impact, in turn, can generate loss of important agroecosystem services, e.g. biological pest control or soil fertility agents that could lead to the degradation of the quality and quantity of agricultural production.

The Mediterranean basin is a particular example of agricultural land use, where human intervention takes place for millennia [5], with olive groves being a dominant landscape feature cultivated in different pedoclimatic zones, predominantly hills or plains [6]. The olive agroecosystem frequently undergoes modifications driven by several types of agronomic practices [7], imposing a significant effect on several parts of biodiversity, especially ground-dwelling fauna $[8,9,10]$. The soil arthropod community is an important asset for the olive agroecosystem. They may deliver substan- 
tial agroecosystem services, functioning as pest control and nutrient cycling agents [11, 12, 10], while certain fractions of arthropod fauna, like Coleoptera, can become useful bioindicators, as they respond to ecosystem modifications due to external pressures [7].

Although olive production of major importance for several Mediterranean countries and territories, recognized as biodiversity hotspots, specialized studies on the biodiversity patterns in olive orchards are rather limited [13, 14, 10], especially in Greece. Indeed, patterns of biodiversity and ecological functioning in agroecosystems are not sufficiently known for several areas or taxa, in order to guide sustainable farming approaches [15]. Previously contacted research $[10,16]$ has provided clues that the different zones of olive cultivation, namely hills and plains, can be discriminated with regards to their agroecological features, such as biotic and abiotic factors, elevation and landscape attributes, when the effect on important fauna, like arthropods, is considered. Therefore, the zone of cultivation may correspond to diverse agricultural landscapes and distinguishable management approaches, with hills being regarded as less suitable for intensive farming practices and inputs, because of limitations generated by several terrain and pedoclimatic conditions $[6,17]$.

The present study was planned in order to confirm and expand previous findings $[18,10]$ on the patterns of ground-dwelling arthropod community in olive orchards, located at hills and plains. Consequently, the objective was set as to monitor the soil arthropod community, expanding the study sites and production periods, and focusing deeper on important taxa, such as Coleoptera, by hypothesizing that their abundance and diversity would be differentiated with regards to the zone of cultivation.

\section{Methods}

\subsection{Study sites and sampling}

The study took place in twelve olive orchards located in the area of Messara $\left(35^{\circ} 01^{\prime} \mathrm{N}, 24^{\circ} 49^{\prime} \mathrm{E}\right)$, southern Crete, Greece, a representative olive production region. The orchards were selected on the basis of expanding previous research carried out in the area [19, 20,18]. Accordingly, they were equally allocated in the two different zones of cultivation, i.e. hills and plains, differentiated upon elevation, terrain, abiotic (soil type and fertility, rainfall, temperature, humidity) as well as biotic environment (fauna and flora). Additionally, the intensity of management applied in the different zones is considered to be differentiated, as farming in hills is less suitable for intensive soil practices and inputs, such as irrigation, due the limitations of terrain and pedoclimatic conditions [6, 17]. All orchards were commercially managed for at least 30 years, planted with "Koroneiki" olive tree variety, one of the prevailing Greek olive cultivars. Their average size was 0.52 ha, ranging from 0.27 to 1.14 ha, considered typical for the area (Table 1 ). A total of 10 weekly measurements took place on the course of the study (autumn 2019 to spring 2020), including autumn and spring sampling, coinciding with the optimal arthropod activity in the olive agroecosystem.

Table 1. Attributes of olive orchards under study in the different zones of cultivation

\begin{tabular}{|c|c|c|c|c|c|c|}
\hline $\begin{array}{l}\text { Orchard } \\
\text { Nr }\end{array}$ & $\begin{array}{c}\text { Zone of } \\
\text { cultivation }\end{array}$ & $\begin{array}{c}\text { Area } \\
\text { (ha) }\end{array}$ & $\begin{array}{c}\text { Slope } \\
(\%)\end{array}$ & $\begin{array}{c}\text { Year of } \\
\text { plantation }\end{array}$ & $\begin{array}{l}\text { Planted } \\
\text { variety }\end{array}$ & $\begin{array}{l}\text { Tree density } \\
\text { (per ha) }\end{array}$ \\
\hline 1 & hills & 0.51 & 1.61 & 1995 & Koroneiki & 206 \\
\hline 2 & hills & 0.33 & 1.54 & 1995 & Koroneiki & 198 \\
\hline 3 & hills & 0.66 & 1.68 & 1992 & Koroneiki & 228 \\
\hline 4 & hills & 0.29 & 1.52 & 1992 & Koroneiki & 205 \\
\hline 5 & plains & 0.38 & 0 & 1980 & Koroneiki & 209 \\
\hline 6 & plains & 0.28 & 0 & 1982 & Koroneiki & 211 \\
\hline 7 & hills & 0.34 & 2.43 & 1990 & Koroneiki & 216 \\
\hline 8 & hills & 0.27 & 1.34 & 1980 & Koroneiki & 220 \\
\hline 9 & plains & 1.11 & 0 & 1991 & Koroneiki & 210 \\
\hline 10 & plains & 0.54 & 0 & 1991 & Koroneiki & 227 \\
\hline 11 & plains & 1.14 & 0 & 1993 & Koroneiki & 212 \\
\hline 12 & plains & 0.45 & 0 & 1993 & Koroneiki & 219 \\
\hline
\end{tabular}

\subsection{Arthropod monitoring}

Six monitoring stations per hectare were defined in the olive orchards, accomplished by means of pitfall traps (plastic, colorless cups, $7.5 \mathrm{~cm}$ of diameter and $11.5 \mathrm{~cm}$ of height) filled with propylene glycol. The traps were placed, achieving 
minimum terrain disturbance, and left on site for a period of 7 days, either under the tree canopy or between tree rows; in a distance of $1.5 \mathrm{~m}$ from the olive tree trunk, when under canopy, and $4 \mathrm{~m}$ when between tree rows. After each sampling, the arthropods were transported to the laboratory facilities in plastic bags, filtered and cleaned of debris and inorganic material and then examined by stereomicroscope (C-PS, Nikon).

Identification of the sampled arthropods was based on quantifiable morphological characteristics, taxonomized to the order level, besides Chilopoda and Diplopoda (to class level), as an appropriate approach for rapid biodiversity assessments [21]. Coleoptera were further classified at family level, due to their significance and potential role as bioindicators in the olive agroecosystem [7]. Families Scarabaeidae, Carabidae, Staphylinidae, Tenebrionidae, Silphidae, Cucujidae, Ptinidae, Curculionidae, Nitidulidae, Anthicidae, Buprestidae and Geotrypidae. Formicidae were counted separately due to their abundance. Chilopoda, Dermaptera, Diplopoda and Hymenoptera (besides Formicidae) were not included in tables due to their scarcity (less than $0.5 \%$ ), while other not true ground-dwellers retrieved, such as Diptera, Lepidoptera and Mecoptera, were not considered.

\subsection{Data analysis}

The arthropods sample were described in terms of a) total taxa abundance (number of total catches per orchard surface); b) taxa richness (S); and c) diversity indices including the reverse Simpson's Index of diversity (1-D), a common but robust and meaningful descriptor [22] and the Pielou's Index (J), representing community's evenness. Both indices are characterized as especially useful for purposes of communities' comparison [23].

A univariate statistical analysis approach was used to compare the different zones of cultivation, except richness, in terms of the above measures, using SPSS $20.0^{\circledR}$ for Windows. The data were assessed for their normality by means of Shapiro-Wilk test $(\mathrm{p}<0.05)$ and were found to be not normally distributed, even after several transformations. Eventually, the Mann - Whitney non-parametric test was selected to assess the community's differences between the zones of cultivation, with a significance reported at the predefined levels of $\mathrm{p}<0.05$ and $\mathrm{p}<0.01$.

In order to represent visually the species abundance distribution (SAD) in the different zones of cultivation, rank abundance curves (Whittaker plots) were as also formulated as a common but robust informative method [22], for the purposes of the study.

\section{Results and discussion}

\subsection{Total arthropod abundance and diversity}

A total of 28,011 arthropods were captured during the whole study period, classified into 16 taxa (orders and classes), including twelve coleopteran families, all found in both zones of cultivation (Table 2). 14,223 individuals were collected in olive orchards located in the hills, representing $50.82 \%$ of the total catches, and another 13,788 in the plains, representing $49.18 \%$. The difference of total catches between zones was not statistically significant (Table 3 ), also shown in the boxplots generated (Figure 1), accumulatively representing the arthropod abundance for the whole study period. Additionally, the highest catches appeared in spring’s sampling (73.52\%) and then autumn (26.48\%).

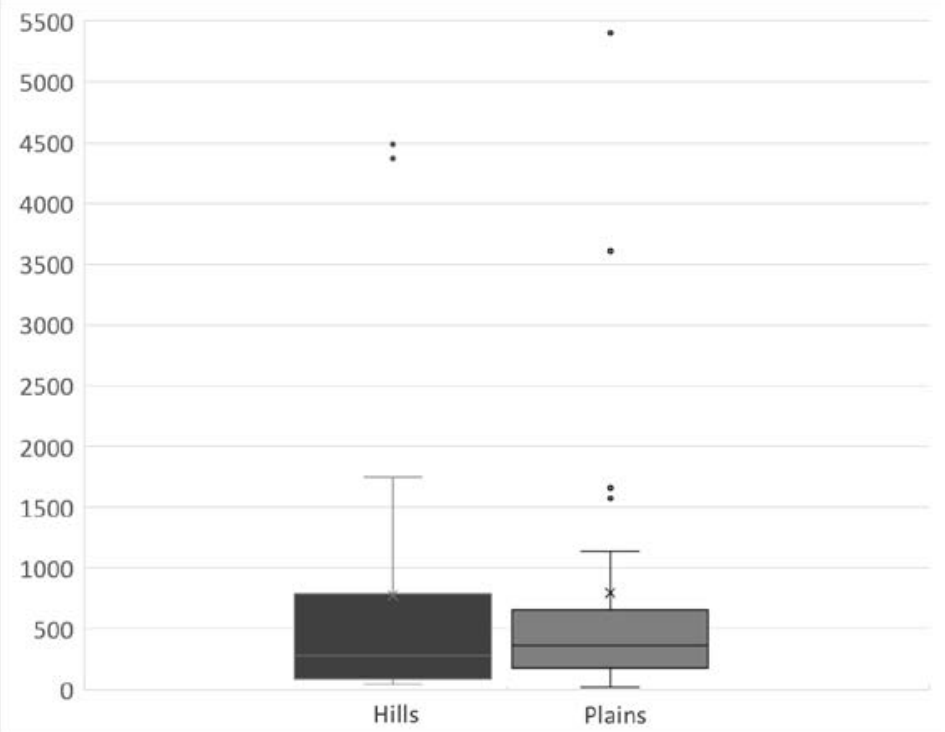

Figure 1. Boxplots of ground-dwelling arthropod abundance in different zones of cultivation, presenting medians and quartiles, accumulatively for the whole study period. 
Table 2. Abundance per hectare of ground-dwelling arthropods, total abundance, richness and diversity indices, for each cultivation zone and the seasonal (autumn, spring) as well as whole monitoring period of the study

\begin{tabular}{|c|c|c|c|c|c|c|}
\hline \multirow{2}{*}{$\begin{array}{l}\text { Monitoring season } \\
\text { Zone of cultivation }\end{array}$} & \multicolumn{2}{|c|}{ autumn } & \multicolumn{2}{|c|}{ spring } & \multicolumn{2}{|c|}{$\Sigma$} \\
\hline & Hills & Plains & Hills & Plains & Hills & Plains \\
\hline Acarina & 179 & 166 & 406 & 388 & 585 & 554 \\
\hline Araneae & 419 & 554 & 1,044 & 583 & 1,463 & 1,137 \\
\hline Coleoptera & 588 & 776 & 3,899 & 4,607 & 4,487 & 5,384 \\
\hline Scarabeidae & 187 & 28 & 616 & 179 & 803 & 187 \\
\hline Carabidae & 160 & 267 & 143 & 401 & 304 & 668 \\
\hline Staphylinidae & 102 & 213 & 352 & 384 & 454 & 597 \\
\hline Tenebrionidae & 71 & 138 & 1,677 & 1,438 & 1,749 & 1,576 \\
\hline Silphidae & 15 & 30 & 203 & 469 & 218 & 499 \\
\hline Cucujidae & 5 & 8 & 64 & 171 & 69 & 179 \\
\hline Ptinidae & 8 & 18 & 34 & 190 & 42 & 208 \\
\hline Curculionidae & 17 & 33 & 309 & 476 & 326 & 509 \\
\hline Nitidulidae & 9 & 35 & 112 & 345 & 121 & 380 \\
\hline Anthicidae & 2 & 5 & 108 & 210 & 109 & 214 \\
\hline Buprestidae & 4 & 6 & 76 & 106 & 81 & 112 \\
\hline Geotrypidae & 7 & 14 & 204 & 240 & 212 & 254 \\
\hline Collembola & 533 & 302 & 199 & 258 & 733 & 560 \\
\hline Dictyoptera & 42 & 16 & 72 & 153 & 113 & 169 \\
\hline Formicidae & 1309 & 1185 & 3,065 & 2,424 & 4,374 & 3,610 \\
\hline Hemipt./Heteropt. & 5 & 4 & 52 & 13 & 57 & 18 \\
\hline Other Hemiptera & 37 & 25 & 213 & 62 & 251 & 87 \\
\hline Isopoda & 275 & 361 & 414 & 1,300 & 689 & 1,661 \\
\hline Opiliones & 286 & 140 & 961 & 205 & 1,247 & 345 \\
\hline Orthoptera & 28 & 41 & 43 & 38 & 71 & 80 \\
\hline Thysanura & 34 & 29 & 17 & 22 & 51 & 51 \\
\hline Total abundance & 3,736 & 3,659 & 10,385 & 10,055 & 14,223 & 13,788 \\
\hline S & 15 & 15 & 16 & 16 & 16 & 16 \\
\hline $1-\mathrm{D}$ & 0.737 & 0.747 & 0.628 & 0.576 & 0.682 & 0.661 \\
\hline $\mathrm{J}$ & 0.782 & 0.777 & 0.616 & 0.556 & 0.699 & 0.667 \\
\hline
\end{tabular}

S: Richness; 1-D: Reverse Simpson's index; J: Pielou's index; $\Sigma$, sum abundance for the whole monitoring period. Other taxa counted and not presented due to scarcity (<0.5\%): Chilopoda, Dermaptera, Diplopoda and hymenoptera (besides Formicidae).

In the Whittaker plots (Figure 2), both zones of cultivation presented similar shallow slopes in all seasons, as an indication of relatively high evenness. The slope in autumn was relatively steeper than in spring and in summer, due to higher taxa dominance, in accordance with previous results [18]. A minor seasonal difference also appears for species richness (1 species) in the autumn's sampling period (see also $S$ values in Table 2).

Statistically significant differences were presented for both diversity indices of Simpson and Pielou's in spring, being higher for orchards located in hills (Table 3). The above results are comparable to previous findings in the study area $[18,10]$ as similar patterns appeared regarding the total abundance, the SAD among monitoring seasons and the significance of difference between the zones of cultivation, while they also present similarities when compared to other studies $[24,8]$. 

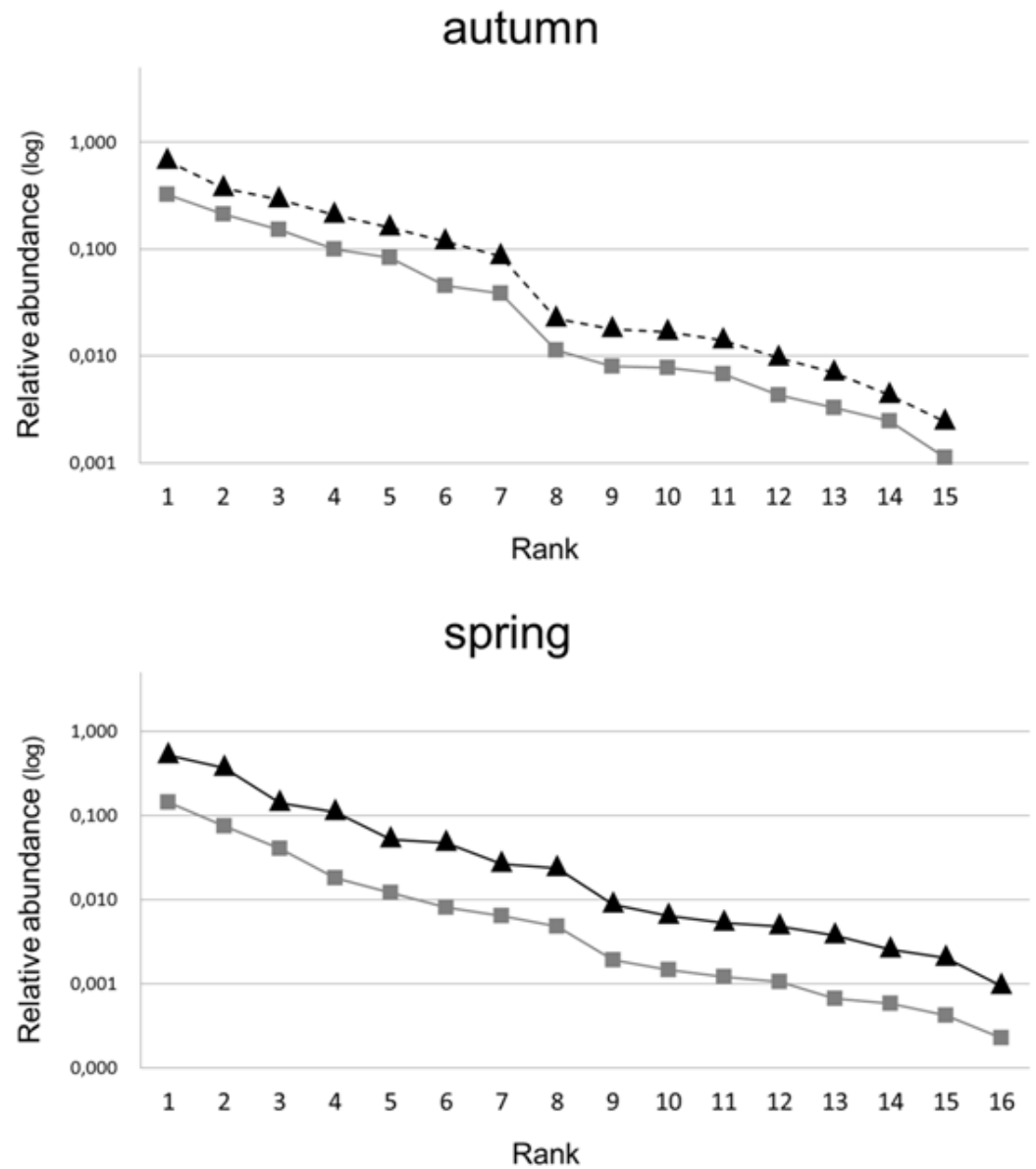

Figure 2. Whittaker plots (Rank abundance curves) of the arthropod community in hills $(\boldsymbol{\Delta})$ and plains ( $\boldsymbol{\square})$ for autumn and spring measurements.

Table 3. Results of the Mann-Whitney test, including $U$ and $Z$, as applied to the comparison between two zones of cultivation (hills and plains) in seasonal samplings (autumn and spring) for the study period

\begin{tabular}{|c|c|c|c|c|}
\hline \multirow{2}{*}{ Taxon } & \multicolumn{2}{|c|}{ autumn } & \multicolumn{2}{|c|}{ spring } \\
\hline & $\mathbf{U}$ & $\mathbf{Z}$ & $\mathbf{U}$ & $\mathbf{Z}$ \\
\hline Acari & 74.5 & 0.134 & 52.0 & -2.281 \\
\hline Araneae & $107.4^{*}$ & 2.201 & 62.0 & -0.433 \\
\hline Coleoptera & $92.0 *$ & 1.278 & $115.0 * *$ & 2.682 \\
\hline Scarabaeidae & $32.5^{* *}$ & -2.328 & $9.0 * *$ & -3.456 \\
\hline Carabidae & $106.0^{*}$ & 2.167 & $131.0 * *$ & 3.599 \\
\hline Staphylinidae & $109.0 *$ & 2.344 & 88.0 & 0.918 \\
\hline Tenebrionidae & $110.5^{*}$ & 2.234 & 99.0 & 1.523 \\
\hline Silphidae & 92.0 & 1.234 & 81.5 & 0.488 \\
\hline Cucujidae & 47.5 & -1.647 & $2.0^{*}$ & -4.088 \\
\hline Ptinidae & 86.0 & 0.799 & $24.0 *$ & -2.832 \\
\hline Curculionidae & 77.5 & 0.378 & 67.0 & -0.187 \\
\hline Nitidulidae & 102.0 & 1.789 & $22.5^{*}$ & -2.884 \\
\hline Anthicidae & 64.0 & -0.465 & $11.5^{* *}$ & -3.456 \\
\hline
\end{tabular}




\begin{tabular}{ccccc}
\hline & & & & \\
\hline Buprestidae & 51.0 & -1.243 & 72.0 & 0.181 \\
Geotrypidae & 104.0 & 1.895 & 97.0 & 1.467 \\
Collembola & 89.0 & 1.343 & 74.0 & 0.478 \\
Dictyoptera & 81.0 & 1.294 & 79.0 & 0.378 \\
Formicidae & 5.0 & -1.111 & $41.0^{*}$ & -1.978 \\
Heteroptera & 52.0 & -1.215 & $13.5^{* *}$ & -3.383 \\
Other Hemiptera & 59.0 & -0.784 & $31.0^{*}$ & -2.458 \\
Isopoda & 79.0 & 0.334 & $11.0^{* *}$ & -3.221 \\
Opiliones & $21.5 * *$ & -2.980 & -4.101 \\
Orthoptera & 90.0 & 1.136 & 80.0 & 0.449 \\
Thysanura & 72.0 & 0.897 & 67.5 & -1.588 \\
Total abundance & & & 73.0 \\
1-D & 51.0 & -1.221 & $14.5^{* *}$ & 0.158 \\
$\mathrm{~J}$ & 103.0 & 1.821 & $21.0^{* *}$ & -3.232 \\
\hline
\end{tabular}

${ }^{*} \mathrm{p}<0.05,{ }^{* *} \mathrm{p}<0.01$ : Predetermined levels of significance used.

\subsection{Specific taxa}

The dominating taxa across the whole monitoring period were Coleoptera, accounting for 35.31\%, Formicidae (28.50\%), Aranae (9.28\%), Isopoda (8.39\%), Opiliones (5.68\%), Collembola (4.62\%) and Acarina (4.07\%), followed by other Hemiptera, Dictyoptera, Orthoptera, Thysanura, Heteroptera, Chilopoda, Dermaptera, Diplopoda and hymenoptera, accumulatively accounting for the rest 4.4\%. Within order Coleoptera, the most abundant families were Tenebrioniade (29.16\%), Carabidae (12.37\%), Staphylinidae (11.04\%), Curculionidae (9.42\%), Silphidae (9.23\%), Nitidulidae (7.03\%), Geotrypidae (4.70\%), Anthicidae (3.97\%), Ptinidae (3.85\%) and Scarabeidae (3.84\%), followed by the less abundant families of Cucujidae (3.32\%) and Buprestidae (2.08\%). Differences of ranking appeared when comparing to other studies in olive agroecosystems elsewhere, with regards to main arthropods' dominance [25, 24, 8, 10]. Nevertheless, the main arthropods collected the olive agroecosystems in the present study are considered to be within the group of the most abundant and frequently appearing taxa in similar research conducted globally [16].

Statistically significant differences between zones of cultivation regarding the specific arthropod abundance, were presented for 3 taxa in autumn, of which two (Aranae and Coleoptera) were higher in the plains and one (Opiliones) in hills, and 6 taxa in spring; 2 higher in the plains (Coleoptera and Isopoda) and 4 in the hills (Formicidae, Hemiptera/Heteroptera, other Hemiptera and Opiliones). The seasonal differentiation between zones of cultivation was again comparable with the previous study conducted in the area of interest [18] and elsewhere [24, 25], indicating spring as a peak season for soil arthropod abundance and in terms of differences.

For Coleopteran families, there were 4 statistically significant differences in autumn (3 higher in plains, 1 in hills) and 6 significant differences in spring ( 5 in plains and 1 in hills) (Table 3). Both the abundance and diversity of the monitored taxa followed similar patterns, as in previous research in the study area [18, 10]. Minor differences appeared with regard to the ranking of most abundant taxa, with Isopoda being ranked as most abundant than Collembola and Opiliones, as previously found in the above mentioned studies $[18,10]$.

\section{Conclusion}

The present study provided significant data on the ground-dwelling arthropod community of the olive agroecosystem confirming previous findings in the study area, by expanding the monitoring period and monitoring sites. The similarity of patterns with regards to the abundance, diversity and richness of arthropods, appearing when different zones of cultivation were compared, indicate a rather robust proof of the discriminatory effect that these zones possess, when specific and important fractions of biodiversity are considered. Likewise, this becomes a potential evidence of the importance of agroecological factors integrated within the different zones of cultivation, such as climatic conditions, soil attributes, farming practices and landscape composition and configuration.

Considering the above, a further, more detailed, analysis of the data generated would be required in order to assess and confirm the interactions of the several biotic and abiotic factors to specific taxa of interest for the olive production, such as functional arthropods delivering important agroecosystem services, with special attention given to factors less 
considered in previous research frameworks, like landscape attributes. The expected outcome would contribute significantly towards a providing biodiversity-based framework for sustainable olive farming, by integrating agroecological guidelines and principles.

\section{Acknowledgements}

This research is co-financed by Greece and the European Union (European Social Fund-ESF) through the Operational Programme «Human Resources Development, Education and Lifelong Learning 2014-2020» in the context of the project "Impact of different management systems and spatial factors on the biodiversity of olive agroecosystems" (MIS 5048171). The authors thank the farmers for their collaboration and access to the olive orchards.

\section{References}

[1] Martin, L. J., Blossey, B., \& Ellis, E. (2012). Mapping where ecologists work: biases in the global distribution of terrestrial ecological observations. Frontiers in Ecology and the Environment, 10(4), 195-201. https://doi.org/10.1890/110154.

[2] Biaggini, M., Consorti, R., Dapporto, L., Dellacasa, M., Paggetti, E., \& Corti, C. (2007). The taxonomic level order as a possible tool for rapid assessment of Arthropod diversity in agricultural landscapes. Agriculture, Ecosystems \& Environment, 122(2), 183-191. https://doi.org/10.1016/j.agee.2006.12.032.

[3] Bailey, D., Schmidt-Entling, M. H., Eberhart, P., Herrmann, J. D., Hofer, G., Kormann, U., \& Herzog, F. (2010). Effects of habitat amount and isolation on biodiversity in fragmented traditional orchards. Journal of applied ecology, 47(5), 1003-1013. https://doi.org/10.1111/j.1365-2664.2010.01858.x.

[4] Kormann, U., Rösch, V., Batáry, P., Tscharntke, T., Orci, K. M., Samu, F., \& Scherber, C. (2015). Local and landscape management drive trait-mediated biodiversity of nine taxa on small grassland fragments. Diversity and Distributions, 21(10), 1204-1217. https://doi.org/10.1111/ddi.12324.

[5] Blondel, J., Aronson, J., Bodiou, J. Y., \& Boeuf, G. (2010). The Mediterranean region: biological diversity in space and time. Oxford University Press.

[6] Kabourakis, E. (1996). "Prototyping and dissemination of ecological olive production systems: A methodology for designing and a first step towards validation and dissemination of prototype ecological olive production systems (EOPS) in Crete”. Published PhD thesis. Wageningen Agricultural University. The Netherlands.

[7] Pizzolotto, R., Mazzei, A., Bonacci, T., Scalercio, S., Iannotta, N., \& Brandmayr, P. (2018). Ground beetles in Mediterranean olive agroecosystems: Their significance and functional role as bioindicators (Coleoptera, Carabidae). PloS one, 13(3), e0194551. https://doi.org/10.1371/journal.pone.0194551.

[8] Santos, S., Cabanas, J., \& Pereira J. (2007). Abundance and diversity of soil arthropods in olive grove ecosystem (Portugal): Effect of pitfall trap type. European Journal of Soil Biology, 43(2), 77-83. https://doi.org/10.1016/j.ejsobi.2006.10.001.

[9] Cotes, B., Campos, M., Pascual, F., García, P. A., Ruano, F. (2010). Comparing taxonomic levels of epigeal insects under different farming systems in Andalusian olive agroecosystems. Applied Soil Ecology, 44(3), 228-236. https://doi.org/ 10.1016/j.apsoil.2009.12.011.

[10] Gkisakis, V., Volakakis, N., Kollaros, D., Bàrberi, P., \& Kabourakis, E. M. (2016). Soil arthropod community in the olive agroecosystem: Determined by environment and farming practices in different management systems and agroecological zones. Agriculture, Ecosystems \& Environment, 218, 178-189. http://dx.doi.org/10.1016/j.agee.2015.11.026.

[11] Orsini, M. M., Daane, K. M., Sime, K. R., Nelson, E. H. (2007). Mortality of olive fruit fly pupae in California. Biocontrol Science and Technology, 17, 797-807. https://doi.org/10.1080/09583150701527359.

[12] Daane, K. M., Johnson, M. W. (2010). Olive fruit fly: Managing an ancient pest in modern times. Annual Review of Entomology, 55, 151-169. https://doi.org/10.1146/annurev.ento.54.110807.090553.

[13] Solomou, A., \& Sfougaris, A. (2011). Comparing conventional and organic olive groves in central Greece: plant and bird diversity and abundance. Renewable Agriculture and Food Systems, 297-316. https://www.jstor.org/stable/44490643.

[14] Gonçalves, M. F., \& Pereira, J. A. (2012). Abundance and Diversity of Soil Arthropods in the Olive Grove Ecosystem. Journal of Insect Science, 12(20), 1-14. https://doi.org/10.1673/031.012.2001.

[15] Stoate, C., Baldi, A., Beja, P., Boatman, N. D., Herzon, I., Van Doorn, A., ... \& Ramwell, C. (2009). Ecological impacts of early $21^{\text {st }}$ century agricultural change in Europe-a review. Journal of environmental management, 91(1), 22-46. https://doi.org/10.1016/j.jenvman.2009.07.005.

[16] Gkisakis, V. D., Volakakis, N. G., \& Kabourakis, E. M. (2020). Agroecological zones as an important driver of canopy arthropod community in olive agroecosystems. Biological Control, 149, 104319. https://doi.org/10.1016/j.biocontrol.2020.104319.

[17] Metzidakis, I., A. Martinez-Vilela, Castro Nieto, G., \& Basso, B. (2008). Intensive olive orchards on sloping land: Good water and pest management are essential. Journal of Environmental Management, 89, $120-128$. https://doi.org/10.1016/j.jenvman.2007.04.028.

[18] Gkisakis, V. D., Kollaros, D., Bàrberi, P., Livieratos, I. C., \& Kabourakis, E. M. (2015). Soil arthropod diversity in organic, 
integrated, and conventional olive orchards and different agroecological zones in Crete, Greece. Agroecology and Sustainable Food Systems, 39(3), 276-294. https://doi.org/10.1080/21683565.2014.967440.

[19] Kabourakis, E. M. (1999). Code of practices for ecological olive production systems. Olivae, 77, 46-55.

[20] Volakakis, N. G., Eyre, M. D., \& Kabourakis, E. M. (2012). Olive fly Bactrocera oleae (Diptera, Tephritidae) activity and fruit infestation under mass trapping in an organic table olive orchard in Crete, Greece. Journal of Sustainable Agriculture, 36(6), 683-698. https://doi.org/10.1080/10440046.2012.672377.

[21] Cotes, B., Campos, M., García, P. A., Pascual, F., \& Ruano, F. (2011). Testing the suitability of insect orders as indicators for olive farming systems. Agricultural and Forest Entomology, 13(4), 357-364. https://doi.org/10.1111/j.1461-9563. 2011.00526.x.

[22] Magurran, A. E. (2004). Measuring Biological Diversity. Blackwell, Oxford.

[23] McGill, B. J., Etienne, R. S., Gray, J. S., Alonso, D., Anderson, M. J., Benecha, H. K., Dornelas, M., Enquist, B. J., Green, J., He, F., Hurlbert, A., Magurran, A. E., Marquet, P. A., Maurer, B. A., Ostling, A., Soykan, C. U., Ugland, K., \& White, E. (2007). Species abundance distributions: moving beyond single prediction theories to integration within an ecological framework. Ecology Letters, 10(10), 995-1015. https://doi.org/10.1111/j.1461-0248.2007.01094.x.

[24] Ruano, F., Lozano, C., Garcia, P., Peña, A., Tinaut, A., Pascual, F., \& Campos, M. (2004). Use of arthropods for the evaluation of the olive orchard management regimes. Agricultural and Forest Entomology, 6(2), 111-120. https://doi.org/10.1111/j.1461-9555.2004.00210.x.

[25] Morris, T. I., Campos, M., Kidd, N. A. C., Jervis, M. A., \& Symondson, W. O. C. (1999). Dynamics of the predatory arthropod community in Spanish olive grove. Agriculture and Forest Entomology, 1, 219-228. https://doi.org/10.1046/j.1461-9563.1999.00030.x. 